\section{Modern microbes}

\section{G.P.C. Salmond \& R. Whittenbury}

Biology of Microorganisms, 4th Edn. By Thomas D. Brock, David W. Smith and Michael T. Madigan.

Prentice-Hall: 1984. Pp.847. Hbk $\$ 51.25, £ 46.70 ; p b k$ \$26.95, £15.95. Microbiology, 4th Edn.

By George A. Wistreich and Max D. Lechtman.

Macmillan, New York*/Collier Macmillan, London: 1984. Pp.909. £40.

"MAINLY old wine in new(ish) bottles" describes, perhaps unkindly, the two textbooks reviewed here. The first, a new edition of Biology of Microorganisms, has emerged with two new co-authors joining the originator of the enterprise, T.D. Brock. The product is a success, building on the previous tried and proved formula. Updating, particularly of the genetics and genetic engineering contributions is the major change from previous editions. Brock, the senior author, is widely regarded as the working general microbiologist's general microbiologist; consequently the content, style and depth of treatment, choice of illustrations, and table and diagram construction fit well with a general microbiologist's conception of what constitutes a good student textbook.

The microbe in its own right holds sway here, we are please to observe; for instance, accounts of structure, function, biochemistry and genetics, and of the microbe in relation to the environment, as a parasite and as a symbiont, all hang together in a way which draws the reader fairly painlessly into the complexity of modern microbiology. In all there are 19 chapters, with useful appendixes, a glossary and a reasonably comprehensive index. A particularly useful chapter is the last one, which describes representative prokaryotic groups and is, in effect, a series of compact essays conveying the essential biology and the unique attributes of each group. This book compares well with the other leaders in the field and is a strong contender for adoption by undergraduates reading courses in which microbiology is a significant component.

Wistreich and Lechtman's Microbiology, also in its fourth edition, represents a brave but, in our eyes, unsuccessful attempt to produce a modern balanced textbook of general microbiology. The book is organized into eight parts; the relative emphasis on the constituent subjects, however, is very uneven. For example Part II is designed to inform on the wide topics of growth, cultivation, metabolism and genetics. This covers only three chapters $(6,7$ and 8$)$ ac-

*See footnote $\mathrm{p} .40$ counting for about 75 pages. On the other hand, medical microbiology and immunology start at Chapter 19 and go through to the end of Chapter 28, taking approximately half of the book. The rest of the book covers various matters, including microbial ecology, industrial microbiology, cell structure and function, and virology.

Perhaps worse than the imbalance in treatment is that the text is superficial in terms of content. Indeed, many parts of the book are likely to be totally misleading, either due to bad grammar or errors of fact. Chapter 8 on microbial genetics is a particularly illuminating example on both counts. It is littered with confusing information, contains mistakes and is badly out of date (for instance, no mention is made of yeast genetics). The poor balance of the book shows up even here where only four pages are dedicated to the topic of genetic manipulation - probably the cornerstone technique of modern biology!

There are some good points to the book, however. On the whole, it is easy to read, there is a wealth of diagrams in both blackand-white and colour, and the photographs are of a high standard. Each chapter begins by listing the things that you should know, and ends (in a form suspiciously like a list of examination questions) with a summary of the salient points plus questions and suggestions for further reading. Our impression, then, is that although this is an excellent microbiology "picture book" the very heavy emphasis on things medical severely perturbs its balance.

G.P.C. Salmond is a Lecturer and R. Whittenbury a Professor in the Department of Biological Sciences at the University of Warwick.

\section{Bodily functions}

Ole H. Petersen

Anatomy and Physiology, Vol.1, 2nd

Edn.

By Edwin B. Steen and Ashley Montagu. Barnes and Noble/Harper \& Row: 1984. Pp.406. Pbk \$6.95, f4.95.

Essentials of Human Anatomy and Physiology.

By Elaine Nicpon Marieb.

Addison-Wesley: 1984. Pp.355. Pbk

$\$ 17.95, \mathrm{fl}$.

Physiology of the Human Body, 6th Edn. By Arthur C. Guyton.

Holt Saunders/Holt, Rinehart \&

Winston: 1984. Pp.691. Hbk £32.50, \$37.95; pbk $£ 8.50$.

Essentials of Physiology, 2nd Edn.

By J.F. Lamb, C.G. Ingram, I.A.

Johnston and R.M. Pitman.

Blackwell Scientific/C. V. Mosby: 1984.

Pp.465. Hbk \$18.95; pbk $£ 12.50$.

IN THE preface to Guyton's Physiology of the Human Body it is correctly stated that ". ... physiology continues in a dynamic stage of discovery with new knowledge of basic physiological concepts generated each day". Unfortunately, these new concepts do not figure prominently in any of the four textbooks reviewed here, and this is clearly due to the practice admitted in the preface to Lamb et al. 's Essentials of Physiology: "The reference list included is generally that which we found useful and usually consists of other secondary references, i.e. larger texts, monographs, etc". In other words, authors of physiology textbooks mostly get their information from other textbooks of physiology.

Steen and Montagu's Anatomy and Physiology is not a real textbook, but more a compendium of basic anatomical and physiological facts presented in a smallformat paperback. It is in two volumes, but at present only Vol. 1 covering blood, cir- culation and the muscular and digestive systems is available. The index is not bad and when the companion volume appears this work could well be useful for lastminute revision purposes.

Essentials of Human Anatomy and Physiology is designed to meet the needs of students in the allied health fields and as such is in direct competition with the more attractive Human Anatomy and Physiology by Solomon and Davis which was reviewed last year (Nature 308, 129; 1984). The anatomy sections are better than those dealing with physiology, in which basic errors can be found; for example the figure illustrating exchange of oxygen and carbon dioxide between tissues and capillaries indicates wrongly that the red cells are only concerned with oxygen and that all carbon dioxide is transported in the plasma.

Guyton's Physiology of the Human Body, now appearing in its sixth edition, is a thoroughly professional book with particularly good black-and-red diagrams and a text which is easy to read. It covers the same ground as Textbook of Medical Physiology by the same author, but with less emphasis on medical aspects. Each chapter starts with a brief overview summarizing the most important points and ends with a short list of questions and references. However, in spite of the addition of some new references, the book could essentially have been written 20 years ago. Key topics such as control of the heart, nerve action potential and transport in the kidney tubules are discussed without any reference to the important results obtained with the new methodologies of recent years. This can make the presentation unnecessarily complicated, when, for example, the electric action potential is explained in terms of ill-defined permeability changes instead of through opening and closure of specific ion channel molecules in the plasma membrane.

Unfortunately, Lamb et al. 's Essentials of Physiology, which is aimed at medical, 